\title{
The Recurrence Interval Difference of Power Load in Heavy/Light Industries of China
}

\author{
Chi Zhang ${ }^{1}$, Zhengning Pu ${ }^{1, *}$ (D) and Jiasha Fu ${ }^{2,3, *}$ \\ 1 School of Economics and Management, Southeast University, Nanjing 211102, China; anhuizhc@outlook.com \\ 2 Research Institute of Economics and Management, Southwestern University of Finance and Economics, \\ 55 Guanghuacun Street, Chengdu 610074, China \\ 3 Survey and Research Center for China Household Finance, Southwestern University of Finance and \\ Economics, 55 Guanghuacun Street, Chengdu 610074, China \\ * Correspondence: puzhengning@seu.edu.cn (Z.P.); fujiasha@chfs.cn (J.F.); \\ Tel.: +86-138-1398-0089 (Z.P.); +86-138-1167-2308 (J.F.)
}

Received: 25 October 2017; Accepted: 31 December 2017; Published: 3 January 2018

\begin{abstract}
The significant fluctuation of industrial electricity consumption has a high impact on power load, which makes the research on recurrence intervals between extreme events of theoretical and practical significance. The study uses a high-frequency data of heavy and light industries and employs recurrence interval analysis in different thresholds. We find that the reoccurrence interval of volatility can fit with the stretched exponential function and the probability density functions of recurrence intervals in various thresholds shows a scaling behavior. Then, the conditional probability density function and the multifractal detrended fluctuation analysis demonstrate the existence of short-range correlation, long-range correlation, and multifractal properties, respectively. We further construct a hazard function, introduce recurrence intervals into VaR calculation and establish a functional relationship between average recurrence interval and threshold. Following this result, we also shed light on policy discussion for multi-industrial electricity supply management.
\end{abstract}

Keywords: electricity fluctuation; recurrence interval analysis; risk estimation

\section{Introduction}

Over the past few decades, China has snowballed and surpassed Japan in 2010 to become the world's second-largest economy [1]. As for energy consumption, China's electricity consumption has also exceeded the United States in 2011 and ranked number one in the world [2]. In 2016, China's total electricity consumption was 5.92 trillion $\mathrm{kWh}$ with an annual growth rate of 5.0\%. Figure 1 shows the proportion of electricity consumption of each industry in China. Compared to 2015, electricity consumption of the tertiary industry increased by $11.2 \%$ and continued to maintain a high growth rate, indicating that service consumption led the growth of China's economy. The electricity consumption of urban and rural household industry, secondary industry, and manufacturing industry increased by $10.8 \%, 2.9 \%$, and $2.5 \%$, respectively. For the four major energy-consuming sectors (Steel, Nonferrous Metals, Building Materials, Chemistry), the electricity consumption barely increased. Such non-increase is because it is apparently for equipment manufacturing, emerging technologies, and mass consumer goods industries, reflecting that the readjustment and upgrading of the industrial structure have a positive effect and the power consumption structure is continuously optimized. By the end of 2016, China's total power generation installed capacity was 1.65 billion $\mathrm{kW}$ with an annual increase of $8.2 \%$, which further aggravated overcapacity in some areas. The non-fossil energy generation continued to increase, and the utilization of thermal power equipment further reduced to 4165 hours, which is the lowest since 1964. In summary, the overall electricity supply and demand in China was loose with a relative surplus in some areas [3]. Regarding price, the electricity price for industries is negotiated 
in most times which varies in different regions. For example, we can see from Figure 2 that the price in developed areas such as Shanghai is higher than that in developing areas like Xinjiang (See http:/ / www.askci.com/news/chanye/20161020/13442871189.shtml).

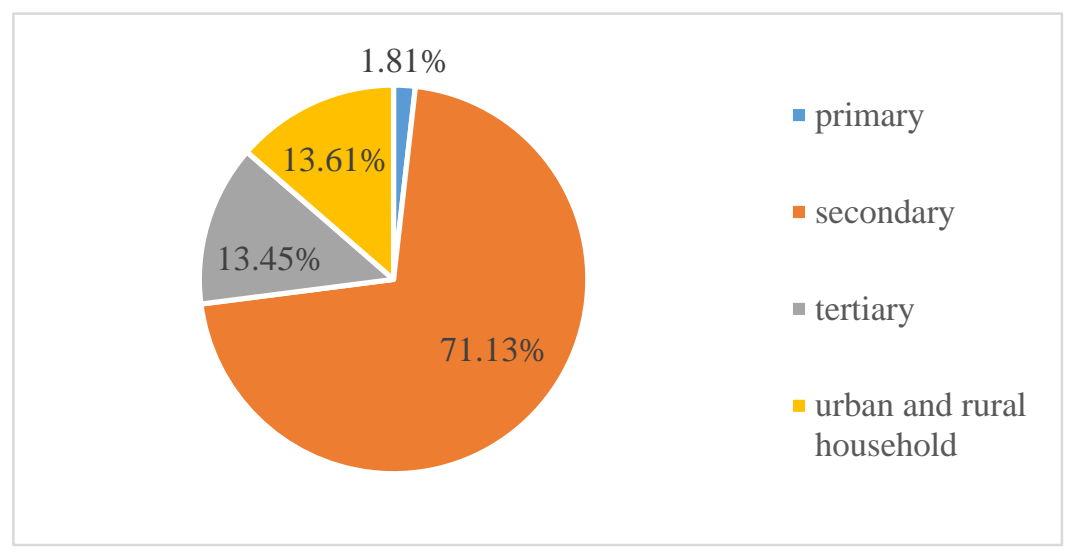

Figure 1. China's electricity consumption of each industry in 2016.

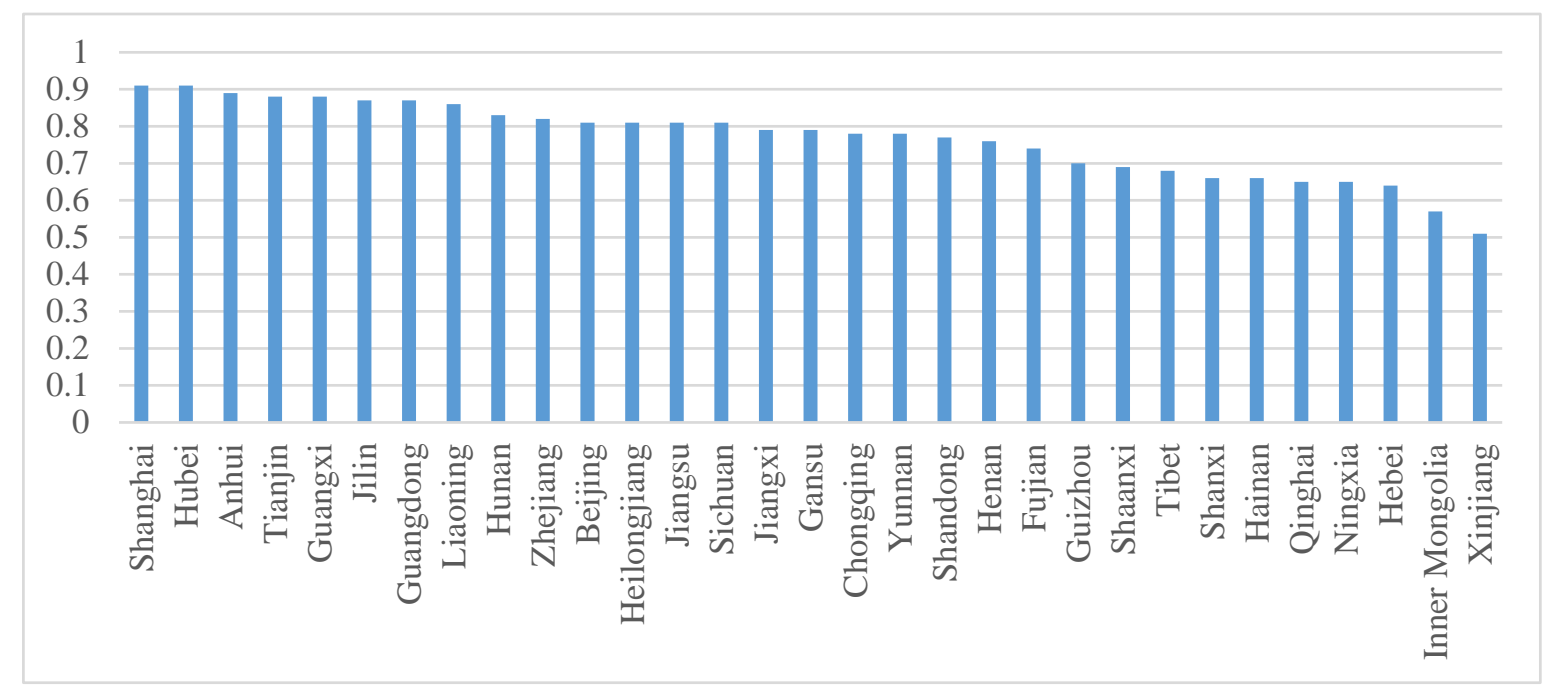

Figure 2. Price of industrial electricity in various provinces of China in late August 2016 (Unit: Yuan).

At the same time, the complexity of power consumption structure was also rising all over the country, which made regional electricity management a huge challenge both for public administrations and for power supply corporations. Therefore, since the year 2015, China has started a new round of electricity reform, which mainly included projects like power transmission, distribution price reform, energy market construction, electricity trading institution establishment and electricity supply reform. All of these projects require China's electricity supply companies to rebuild their organization structure and upgrade management plans to deal with more intense market competition. Accurately predicting the trend and change of regional/sector electricity consumption by energy consumption modeling can help electricity companies optimize their management strategies, reduce operation cost and prevent potential power supply risks, and can also help the nation save resources, avoid waste and reduce infrastructure over-investment.

As shown in Figure 1, China's energy consumption concentrated in the industrial sector. For enterprises belonging to different industry sectors (i.e., heavy industry or light industry), the power loads have quite a different magnitude. As is well known, people are more interested in large electricity fluctuations than small ones. For example, in a particular area, if the power load of light industry 
enterprise reaches its peak, the power supply network in the area will not feel the pressure. However, if a heavy industry enterprise exceeds its peak power, this may pose an enormous risk of grid paralysis or even serious accidents, which would usually spread and cause an immeasurable damage and suffering to the society. Such differences require power supply companies to differentiate their load management strategies for different industries. Hence, analysis and comparison of heavy/light industrial electricity consumption patterns, especially the extreme electricity events will provide a theoretical foundation and practical guidance, which can help power supply companies avoid grave accidents, ensure the stability of power supply operation and keep power transfer equipment safe.

Due to the availability of real-time power load data, forecasting extreme events in electricity market becomes possible. In this paper, we use 15-min high-frequency electricity load data from two companies (one belongs to heavy industry, another belongs to light industry) for the city of Nanjing in China to study the recurrence pattern between fluctuations. The questions we tried to answer are as follows: How to describe the volatility behavior? If a massive volatility occurred, will it happen again or not? When will the next significant fluctuation occur? How to estimate the occurrence probability and the time interval between two extreme events?

Our study, therefore, contributes to the literature in the following perspectives. First, among plenty studies that have done in the electric field, research on the electricity consumption pattern between heavy and light industry is rare. So far as we know, this is the first paper to focus on the industrial difference of power load from a policy perspective. Second, as a major city with a fast-growing economy in China, Nanjing, the capital of Jiangsu province, has an urgent demand for energy especially electricity. Research on Nanjing can be a useful guide for other emerging first-tier cities in China. Most previous studies on Jiangsu area only use daily data [4-7] while here we use high-frequency data which can help to capture more specific properties. Finally, different from many studies using power law to model rare events in many fields [8-13] including electricity markets [14,15], we use the stretched exponential function to analyze the extreme events [16-18]. Unlike the power-law which displays a linear relationship in log-log plots, stretched exponential function has a significant curvature in log-log plots which can better describe the natural phenomena in nature and economy [19].

The rest of this paper is arranged as follows: Section 2 reviews current studies. Section 3 describes the method and presents basic statistics of the data set. Section 4 initials an empirical research, including distribution function, scaling properties, memory effect and risk estimation. Section 5 delivers management policy implications discussions for China's power supply company. Section 6 concludes.

\section{Literature Review}

Currently, plenty of models have been applied to forecast electricity load, and most of them can be classified into three categories: regression, data series analysis, and neural network.

Regression analysis considered power load as a dependent variable of other factors, such as weather or holidays [20], and tried to construct a function relationship between electricity load and other influence factors [21]. Such results were confirmed by the reality in some residential areas [22]. With technology evolving, a decomposition model was applied, and many vital factors were pinned in the evolution progress [23]. Also, GDP [24], income [24], seasonal variations [25], etc. were all confirmed to be relevant to electricity load forecast by regression analyses. In the 21st century, the emergence of smart technology could help researchers grab high-frequency data from a personal level and add human behavior into a regression model to improve the forecast accuracy $[26,27]$. Briefly, regression analysis aimed to describe the quantitative relationship between the observed variables in statistics, however, it could not capture the spatiotemporal variation and is sometimes restricted by the data volume.

Time series analysis considered that the electricity load pattern was a time series signal, which could be used to predict the future load with historical data [28]. With technology development, various time series models have been proposed [29]. Carmine et al. [30] applied time-series analysis model to the electricity consumption of public transportation in Sofia (Bulgaria) in 2011, 2012 and 2013 and 
detected a periodic pattern, which could be used to improve electricity management. Dong et al. [31] proposed a hybrid model to predict residential load hour and day ahead with five different algorithms and the results improved prediction accuracy. Liang and Liang [32] proposed a mathematical hybrid method to analyze electricity demand in China and predicted the demand evolution in the next five years from 2016 to 2020. Though the predictable time spectrum of time series analyses varies from one hour to several years, the claim to the accuracy of historical data was very high. The algorithm might be complex and unstable in some cases. Additionally, when applying in short-term power load forecast, it was not sensitive to weather factors and not able to solve the inaccuracy problem caused by meteorological factors.

Artificial neural networks (ANNs) could estimate future loads with previous data without the presumption of the functional relationship between electricity load and other relative variables [29]. Compared with traditional methods, ANN was better at dealing with nonlinear relationships [33]. At present, the neural network was well applied in various fields including electric load forecasting [34-37]. Moreover, the integration of ANN and other methods has become a research hotspot. ANN was integrated with fuzzy logic [38], genetic algorithm [39], wavelet analysis [40,41], chaos theory [42], grey system [43], etc. However, ANN has its limitations: it is hard to avoid learning deficiency or over-fit phenomena, and the convergence speed is slow and easy to fall into local minima.

In this paper, we will use a different method: recurrence interval analysis (RIA), which belongs to time series analysis, to investigate the fluctuation characteristics of heavy/light industries. RIA has been widely used to analyze extreme events in many fields, for example, climate [44], earthquake activities [45,46], heartbeat monitoring $[47,48]$ and financial volatility $[49,50]$. These events occur with a high magnitude and low probability. For a long time in the past, extreme events were assumed to be spontaneous, namely mutually uncorrelated. Nevertheless, researchers show that extreme events do not occur independently; contrarily, they gather and happen in a relatively short period. RIA focuses on the electricity fluctuation rather than the power load, which is good at depicting the volatility pattern and estimating the risk. Assuming occurrence probability of future events is constant and dependent on past events, RIA can estimate the probability of the events to happen again in the future. Here, Recurrence interval means the time interval between two consecutive events beyond (under) one certain threshold, which can be positive or negative. It is also powerful to characterize the fluctuation behaviors in different magnitudes [51] and sometimes even to construct a relationship among them.

\section{Data Description}

The data in this paper is extracted from the transformer of each corresponding area in 15-min frequency, and we chose two enterprises, which represented heavy and light industries, respectively. In the national economy, heavy and light industries refer to the sectors which provide capital and consumption goods, respectively. Heavy industry includes steel industry, metallurgical industry, machinery, energy (electricity, oil, coal, natural gas, etc.), chemistry and materials science. These industries provide technical equipment, power and raw materials for all branches of the national economy. Light industry mainly includes foodstuff, textile, leather, papermaking, daily chemical industry, culture, education and sporting goods industry. According to the data from National Bureau of Statistics of China, the finished goods of heavy and light industry were 2.608 and 1.341 trillion yuan in 2015, respectively (See http:/ / data.stats.gov.cn/easyquery.htm?cn=C01\&zb=A0E010D\&sj=2015). In this paper, we select a steel/textile enterprise to represent the heavy/light industry. The sample period was from 1 January 2016 through 31 December 2016 and finally we ended up with 35,316 electricity load observations. The returns of time series are calculated by taking differences of the load as:

$$
r(t)=l(t)-l(t-\Delta t)
$$

where $l(t)$ is the electricity load (unit: $\mathrm{kW}$ ) of the $t$ th time and $\Delta t=15$ because the data is 15 -min frequent. Figure 3 shows the returns of heavy/light industries and Figure 4 is the frequency distribution of fluctuation. The statistics are summarized in Table 1. 
Figures 3 and 4 and Table 1 show that the returns are not normally distributed. One has a sharp peak, and another has platy kurtosis. Though their average and standard deviation values have magnitude difference, the two industries also have common properties, like skewness. From Figure 3, it is clear that there are zero values in Figure $4 b$, which means in a specified period, the light industry enterprise was not in operation. When combining with Table 1 , we can see that even a large company could not operate continually, which is the reason why the minimum values are both zero and why we used different values to describe fluctuation.
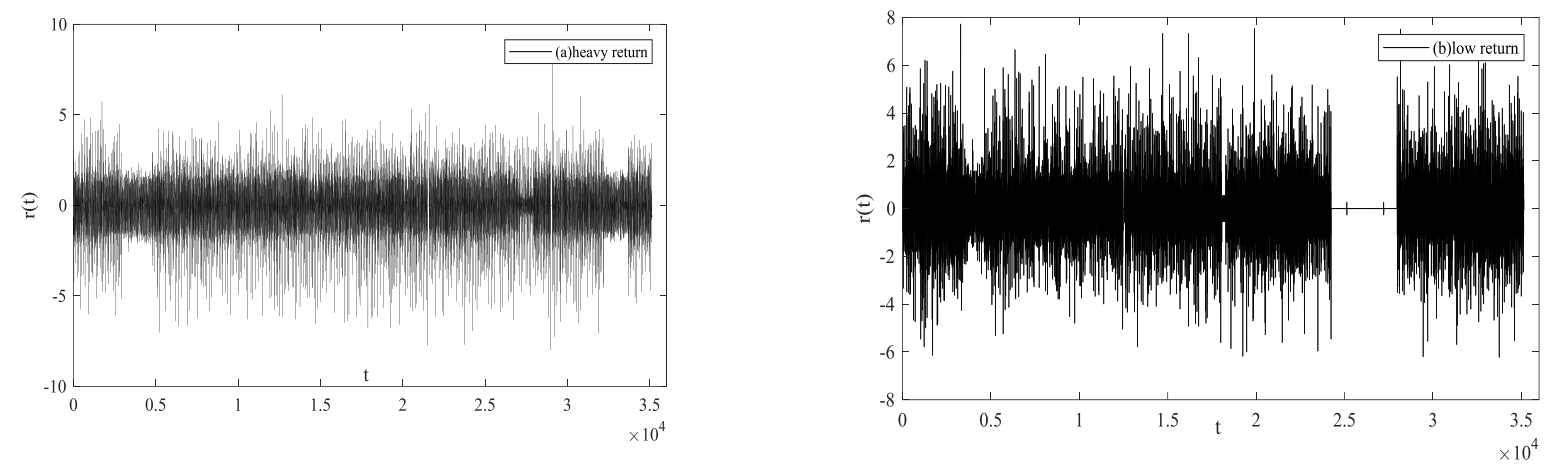

Figure 3. Returns of heavy/light industries. (a) Heavy return; (b) Low return.
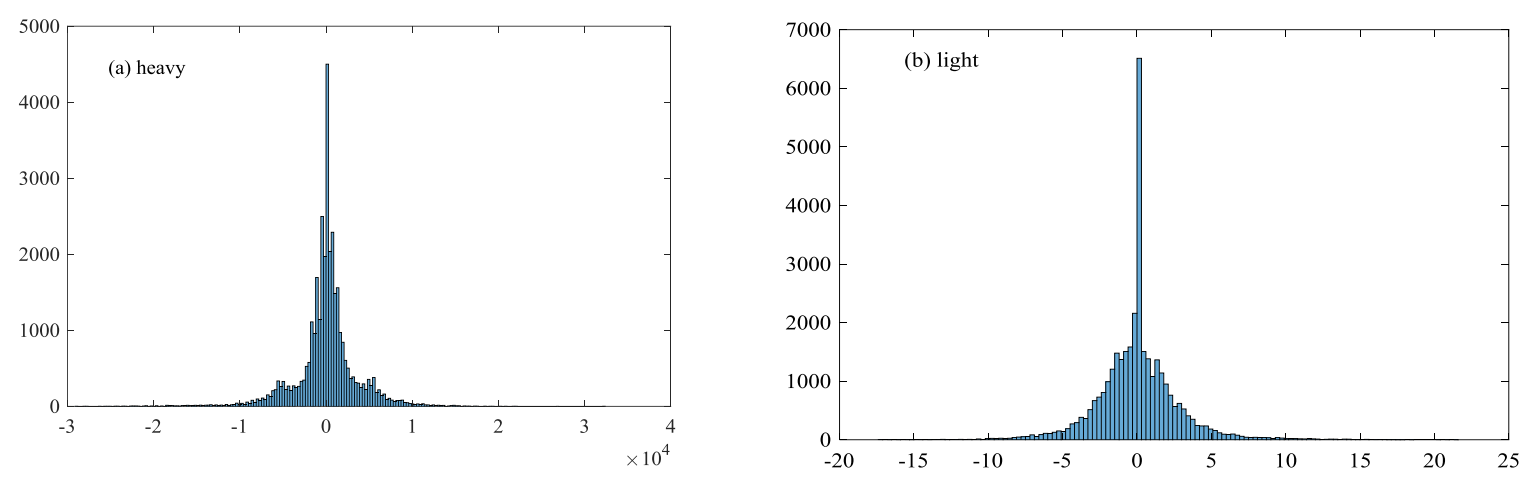

Figure 4. Frequency distribution of fluctuation. (a) Heavy; (b) Light.

Table 1. Statistics of the returns of heavy/light industries.

\begin{tabular}{cccccccc}
\hline & Average & Maximum & Minimum & Std. & Skewness & Kurtosis & Nobs \\
\hline Light & 10.21 & 47.40 & 0 & 8.18 & 0.84 & 3.20 & 35,316 \\
Heavy & $1.54 \times 10^{4}$ & $3.70 \times 10^{4}$ & 0 & $8.70 \times 10^{3}$ & 0.61 & 1.91 & 35,316 \\
\hline
\end{tabular}

The x-ray of Figure 5 is the value of threshold $q$, and y-ray is the number of extreme events of $q ; q$ measures the volatility of the normalized $r(t)$. Due to magnitude discrepancy of electricity consumption between heavy and light industries, we normalize the fluctuation for comparison purposes and the results are shown in Figure 5. It can be clearly seen that the number decreases with an increasing $q$, indicating that a larger fluctuation has less occurring probability, which is in accordance with reality. The slope is getting smaller when q increases for each curve, and there is an intersection point in the figure, indicating that small fluctuations more likely happen in heavy industry and larger volatilities more likely happen in light industry. 


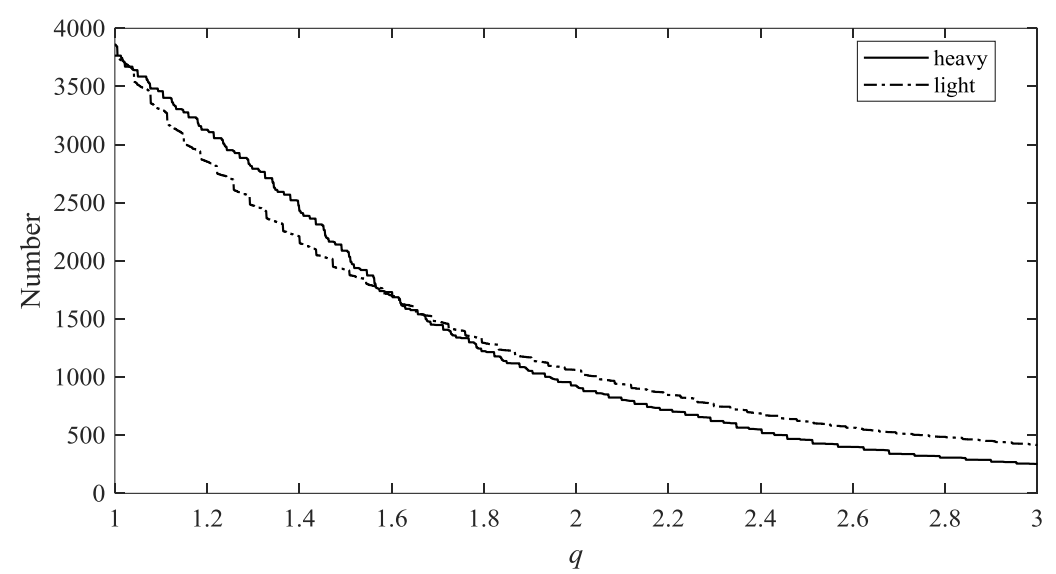

Figure 5. Number of extreme events of different threshold $q$.

\section{Results}

\subsection{Probability Density Function}

Consider $\tau$ as the recurrence interval when threshold is $q$, the overwhelming consensus is that the recurrence intervals of volatility are distributed as a stretched exponential.

$$
f(x)=\alpha \bar{\tau} e^{-(\beta \bar{\tau} x)^{\gamma}}
$$

In Equation (2), $\bar{\tau}$ is the mean recurrence interval that depends on the threshold $q$, where the probability distribution function of recurrence interval $\tau$ is $P_{q}(\tau)$, and $\alpha, \beta, \gamma$ are the parameters [16-18], where $\alpha$ and $\beta$ are the coefficients related to the threshold $q$, while $\gamma$ is the correlation exponent reflecting the long term memory of the recurrence intervals.

We normalize the returns of each series by dividing its standard deviation: $R(t)=\frac{r(t)}{\left[\operatorname{Er}(t)^{2}-E^{2} r(t)\right]^{1 / 2}}$, where $\left[E r(t)^{2}-E^{2} r(t)\right]^{1 / 2}$ is the standard deviation of $r(t)$. For each threshold $q$, we can obtain a data set of recurrence interval $\tau$, and then get the probability density function of $\tau$. The $q$ here is positive $(q>0)$ because our interest is the overload operation of the electrical system. The empirical parameters of the probability distribution function $P_{q}(\tau)$, calculated by maximum likelihood estimation are shown in Table 2.

Table 2. Estimates of the coefficients of stretched exponential functions.

\begin{tabular}{ccccc}
\hline Industry & $\boldsymbol{q}$ & $\boldsymbol{\alpha}$ & $\boldsymbol{\beta}$ & $\boldsymbol{\gamma}$ \\
\hline \multirow{5}{*}{ Heavy } & 1.0 & 0.031 & 0.090 & 0.684 \\
& 1.2 & 0.025 & 0.075 & 0.648 \\
& 1.4 & 0.018 & 0.058 & 0.587 \\
& 1.6 & 0.012 & 0.041 & 0.519 \\
Light & 1.8 & 0.008 & 0.029 & 0.448 \\
\hline & 1.0 & 6.880 & 261.870 & 0.171 \\
& 1.2 & 5.072 & 193.056 & 0.170 \\
& 1.4 & 3.684 & 149.838 & 0.168 \\
& 1.6 & 2.542 & 115.224 & 0.165 \\
& 1.8 & 1.564 & 87.587 & 0.163 \\
\hline
\end{tabular}

Note that the coefficients of the exponent $\gamma$ of large enterprises are in the range between 0.448 and 0.684, while the corresponding exponents of the light enterprises are much smaller within the interval $(0.163,0.171)$. It is obvious that the long-term memory effect in the recurrence intervals of electricity usage in large enterprises dies out faster than that in light companies. 
Figure 6 shows that first, for large fluctuations, $P_{q}(\tau)$ decays slowly, indicating that with $q$ rises, recurrence intervals will be longer, in accordance with the fact that large fluctuations have more long intervals and less short intervals than small fluctuations. Second, when threshold $q$ is fixed, $P_{q}(\tau)$ decreases with increasing recurrence interval $\tau$. This implies that when the previous fluctuation occurred $t$ units of time ago, if $\Delta t_{1}<\Delta t_{2}$, the probability $P_{q}(\tau)$ of the next fluctuation to occur after $\Delta t_{1}$ is larger than $\Delta t_{2}$. The result suggests that if the enterprise suffers a huge electricity load rise, the enterprise should be aware that the probability that if another large load rise occurs within a shorter time interval it is likely to be larger with a longer time interval. Moreover, when recurrence interval is fixed, $P_{q}(\tau)$ increases with $q$. If an extreme event occurs, the probability that another extreme event occurs will be higher for a larger threshold $q$. Last, comparing Figure $6 \mathrm{a}, \mathrm{b}$, we can find for a same threshold $q, P_{q}(\tau)$ decreased faster along with $\tau$ for heavy enterprises than low enterprises, indicating that the probability of large fluctuations of heavy enterprise is less than light enterprise, which in accordance with the fact that heavy industry is less risk-taking to large volatility than light industry.
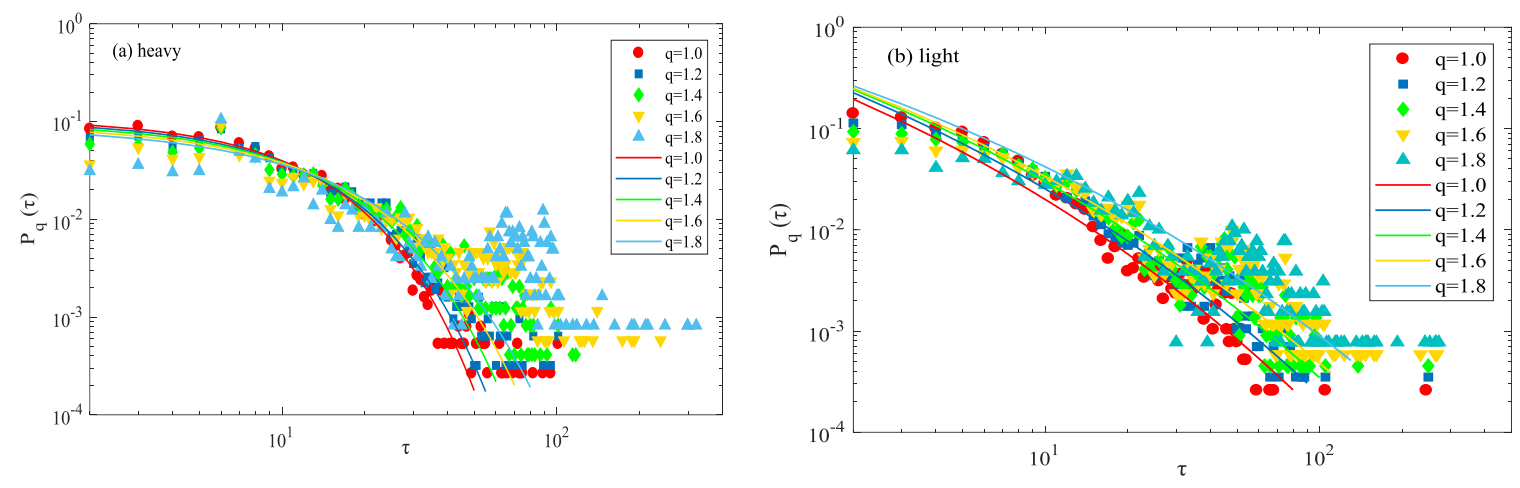

Figure 6. Empirical probability distribution of recurrence intervals with different thresholds. (a) Heavy; (b) Light.

From Figure 6, it can be seen that with $q$ rising, recurrence intervals will be longer, in agreement with the fact that large fluctuations have more long intervals and less short intervals than small fluctuations, which means for large fluctuations, there is a higher probability that the time intervals between two consecutive events will increase.

Besides, by the observations in Table 2 and Figure 6, we find all the probability density function curves have similar shapes, which make us wonder whether there is a scaling behavior between these probability density functions? To examine that, we use Yamasaki et al.'s [52] method. Not only discovering the scaling behavior of events of different thresholds, but it can also efficiently solve the problem of insufficient data.

$$
f_{q}(\tau / \bar{\tau})=P_{q}(\tau) \bar{\tau}
$$

where $\tau / \bar{\tau}$ is scaled recurrence interval and $P_{q}(\tau) \bar{\tau}$ is scaled PDFs. When threshold $q$ changes, $\bar{\tau}$ changes and there is $(d \bar{\tau}) /(d q)>0$, indicating that with volatility increases, the mean time of recurrence interval increases, which is consistent with the fact. If $f_{q}(\tau / \bar{\tau})$ is independent to $q$, then there will be a unique function $f(x)$, for different threshold $q$.

$$
f_{q}(x)=f(x)
$$

Namely, the scaled probability distribution $f_{q}(\tau / \bar{\tau})$ will converge to the single curve $f(\tau / \bar{\tau})$ and recurrence intervals have a scaling behavior. To test that, we picture the scatter diagram of $f_{q}(\tau / \bar{\tau})$ as the function of $\tau / \bar{\tau}$ in Figure 7. It can be seen that for different thresholds $q, P_{q}(\tau) \bar{\tau}$ converge to one curve regardless of which enterprise it belongs, indicating that there exists a scaling behavior and we can deduce the behavior characteristics of large fluctuations by those of small fluctuations. 

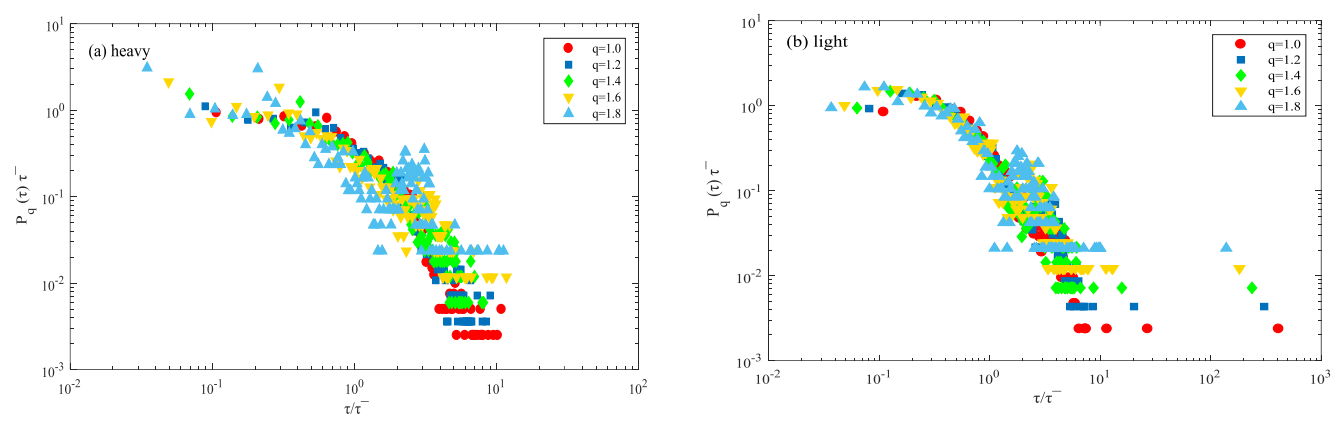

Figure 7. Scaled probability distributions of recurrence intervals with different thresholds. (a) Heavy; (b) Light.

\subsection{Memory Effect}

\subsubsection{Short-Term Memory}

Short-term memory means that small $\tau$ tends to follow small $\tau_{0}$, and big $\tau$ tends to follow big $\tau_{0}$. The conditional probability density functions $P_{q}\left(\tau \mid \tau_{0}\right)$ [52] can be used to reflect the occurrence probability of a recurrence interval $\tau$ immediately after the recurrence interval $\tau_{0}$. If there is no short-term memory, $P_{q}\left(\tau \mid \tau_{0}\right)$ is independent of $\tau_{0}$. However, due to the insufficiency of interval sample, it is impossible to calculate $P_{q}\left(\tau \mid \tau_{0}\right)$ for a single value $\tau_{0}$. In order to obtain more data, we adopt a method based on the idea of coarse-graining [53-55] and calculate $P_{q}\left(\tau \mid \tau_{0}\right)$ for values of $\tau_{0}$ in a certain interval instead of a single value $\tau_{0}$. Specifically, for a given threshold $q$, all the recurrence intervals in the set $T$ are sorted in an increasing order, and then we divide the set $T$ into four non-overlapping subsets with the same size,

$$
T=T_{1} \cup T_{2} \cup T_{3} \cup T_{4}, T_{i} \cap T_{j}=\phi, i \neq j
$$

where $T_{1}$ contains the smallest quarter while $T_{4}$ contains the largest. Then we estimate the conditional probability density functions:

$$
P_{q}\left(\tau \mid T_{i}\right)=P_{q}\left(\tau \mid \tau_{0} \in T_{i}\right)
$$

If there is no short-term memory, we should find

$$
P_{q}\left(\tau \mid T_{i}\right)=P_{q}\left(\tau \mid T_{i}\right), i \neq j
$$

Figure 8 shows the results of $P_{q}\left(\tau \mid \tau_{0}\right) \bar{\tau}$ as a function of $\tau / \bar{\tau}$ for $\tau_{0}$ in the smallest subset $T_{1}$ (filled symbols) and the largest subset $T_{4}$ (open symbols). Obviously, no matter for heavy or light enterprises, $P_{q}\left(\tau \mid T_{i}\right) \neq P_{q}\left(\tau \mid T_{i}\right)$. We also find that $P_{q}\left(\tau \mid \tau_{0} \in T_{1}\right)$ is bigger than $P_{q}\left(\tau \mid \tau_{0} \in T_{4}\right)$ for small $\tau / \bar{\tau}$, while for big $\tau / \bar{\tau}, P_{q}\left(\tau \mid \tau_{0} \in T_{1}\right)$ is smaller than $P_{q}\left(\tau \mid \tau_{0} \in T_{4}\right)$ in Figure 8a,b. There exists very short-term memory in the recurrence intervals.
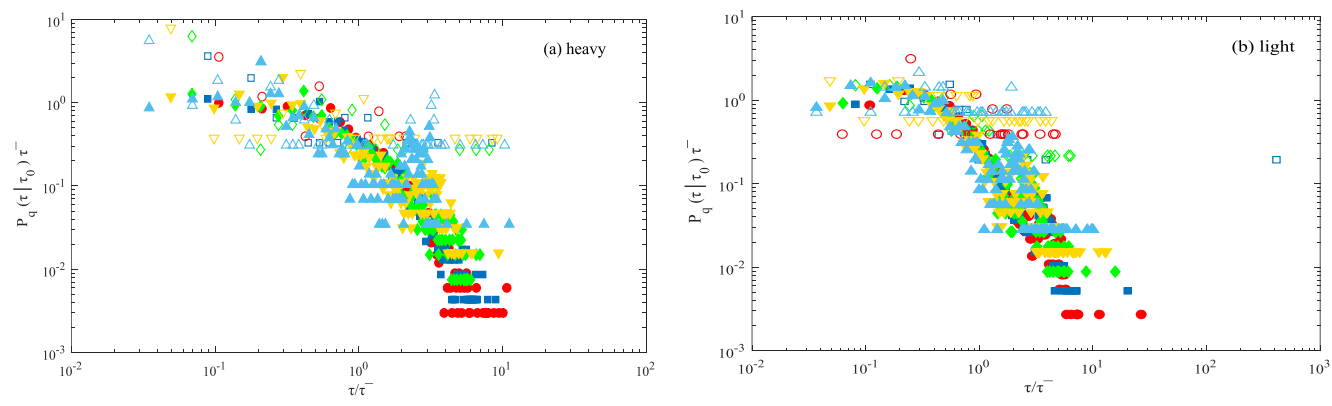

Figure 8. Conditional probability density functions $P_{q}\left(\tau \mid \tau_{0}\right)$ with $\tau_{0} \in T_{1}$ (filled symbols) and $\tau_{0} \in T_{4}$ (open symbols). (a) Heavy; (b) Light. 


\subsubsection{Long-Term Memory}

Experience shows that scaling behavior and short-term memory is usually a foreshadowing of the long-term memory $[56,57]$. To figure out whether there exists long-term memory in electricity use of the high/light industries, we adopt the MF-DFA (multifractal detrended fluctuation analysis) method [56,58-60].

The conventional DFA method invented by Peng et al. (1994) [61], which is used to investigate the statistical self-affinity in time series analysis, but limited to scale the second order statistical moment of one-dimensional fractal time series by computing Hurst exponent.

In mathematics, a fractal is an abstract object used to describe and simulate naturally occurring objects. Artificially created fractals can exhibit similar patterns at increasingly small scales. So far several models applied in electricity market are proposed based on fractal theory [62-65]. With the study objects becoming increasingly diverse and complicated, fractal with a single exponent (the fractal dimension) is not capable of describing the dynamics in reality, like coastlines length, stock market time series, heartbeat dynamics, real-world scenes, etc. A continuous spectrum of exponents (singularity spectrum) is needed and then emerges the multifractal [66-69]. A multifractal system is a generalization of a fractal system and can be discovered in nature, which we can apply in a variety of practical situations such as electricity demand [70,71].

In 2002, Kantelhardt et al. [72] combined multifractal with DFA and put forward the MF-DFA, which can describe the multifractal characteristics of time sequence and computes the $\mathrm{H}(p)$ for all $p$-order statistical moments. As one practical method to test whether a non-stationary time series has multifractal characteristics, MF-DFA is widely applied in the financial markets [68], molecular biology [73], disaster prevention and control [69], power pricing analysis [74,75] and electricity market $[71,76]$. Assume the sample $X=\left\{x_{k}, k=1,2, \ldots, N\right\}$, the specific steps of this algorithm are as follows.

(1) Calculate the accumulated deviation $N$ times of the original data and construct new time series:

$$
Y=\left\{y(i)=\sum_{k=1}^{i}\left(x_{k}-\bar{x}\right), k=1,2, \ldots, N\right\}
$$

where $\bar{x}$ is the average of $X$.

(2) Divide new series $Y$ into forward and backward direction, separately; the length of each unit is $s$, end up with $2 N_{s}$ non-overlapping section with equal length, and $N_{s}=\operatorname{int}(N / s), \operatorname{int}()$ is integer-valued function, which avoids information loss if $N$ cannot be divisible by $s$.

(3) Use least square method for each new subinterval $v\left(v=1,2, \ldots, 2 N_{s}\right)$ to curve-fitting, get first-order or multi-order local trend function $y_{v}(j)$. When $v=1,2, \ldots, N_{s}$, calculate residual sequence of subinterval $v$, when $v=N_{s}+1, \ldots, 2 N_{s}$,

$$
Z_{v}(j)=\frac{1}{s} \sum_{j=1}^{s}\left\{Y\left[N-\left(v-N_{s}\right) s+i\right]-y_{v}(j)\right\}
$$

(4) Calculate $p$-order volatility function of sequence

$$
\begin{gathered}
F^{2}(s, v)=\frac{1}{s} \sum_{j=1}^{s} Z_{v}^{2}(j), v=1,2, \ldots, 2 N_{s} \\
F_{p}(s)=\left\{\begin{array}{c}
\left\{\frac{1}{2 N_{s}} \sum_{v=1}^{2 N_{s}}\left[F^{2}(s, v)^{p / 2}\right]\right\}, p \neq 0 \\
\exp \left\{\frac{1}{4 N_{s}} \sum_{v=1}^{2 N_{s}}\left[F^{2}(s, v)\right]\right\}, p=0
\end{array}\right.
\end{gathered}
$$


when $p=2$, it is standard DFA.

(5) Based on Equation (10), we know $F_{p}(s)$ is positively correlated with $s$, with log-log coordinate, we have

$$
F_{p}(\mathrm{~s}) \sim s^{h_{p}}
$$

where $h_{p}$ is Hurst exponent, for non-stationary time series, only when $0.5<h_{p}<1$, this series has a long-term correlation, indicating that the system has the fluctuation pattern in long-term evolution. When $h_{p}$ is the function of $p, X(t)$ has multiple fractal characteristics.

In Figure 9, there are ten subfigures, and each subfigure has four sub-subfigures, which show the results of MF-DFA, respectively. It can be seen that the $p$-order Hurst exponent of each line is higher than 0.5 in a certain area, suggesting that long-term correlations and multifractal characteristics exist in the recurrence intervals. When $h_{p}<0.5$; it means the volatility is of anti-continuity.
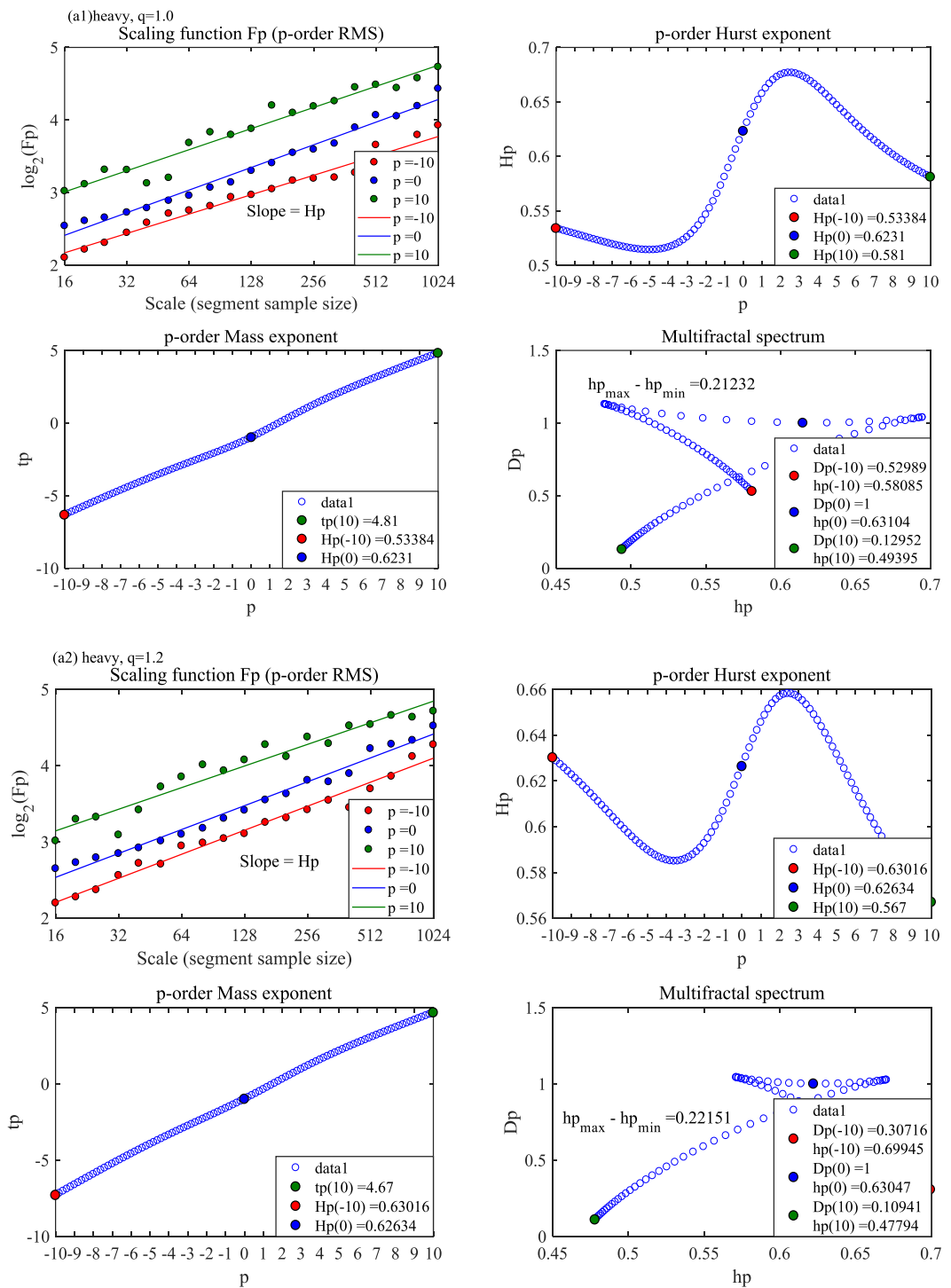

Figure 9. Cont. 

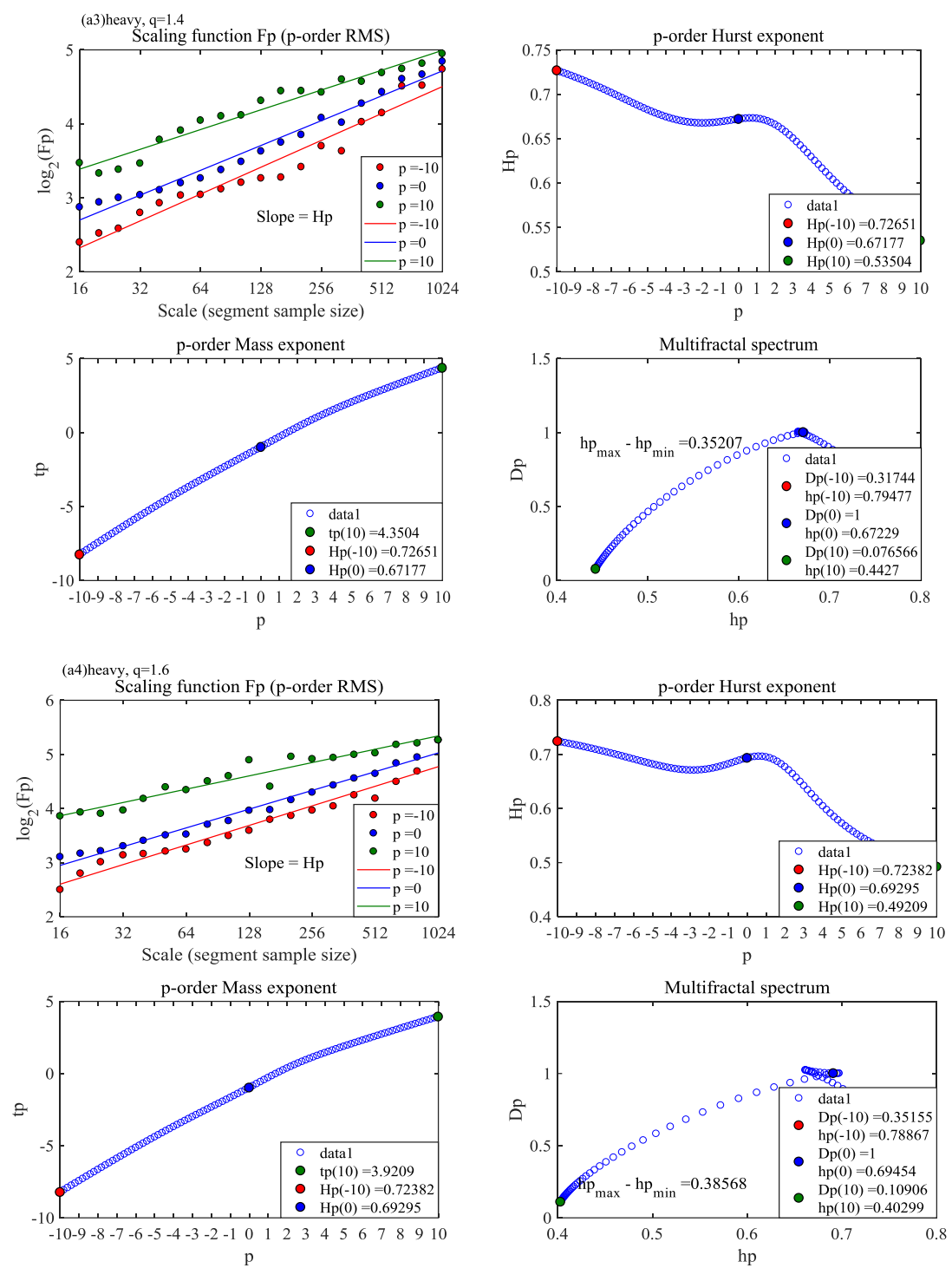

(a5) heavy, $\mathrm{q}=1.8$
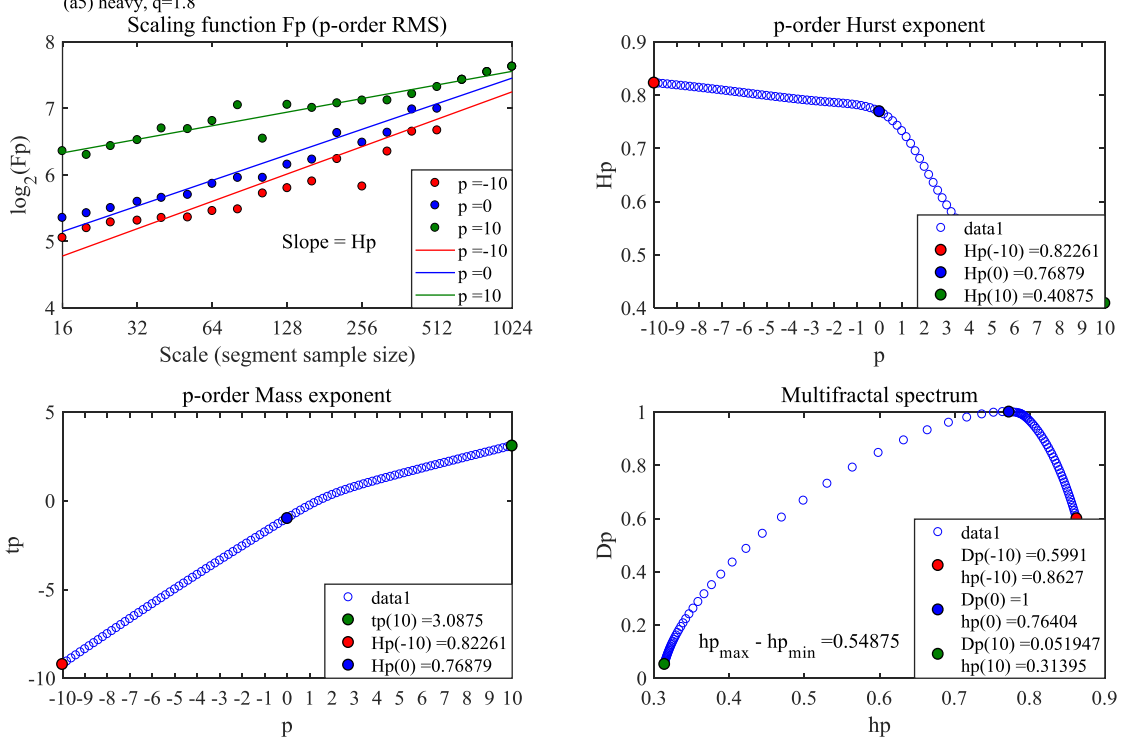

Figure 9. Cont. 
(b1) light, $\mathrm{q}=1.0$

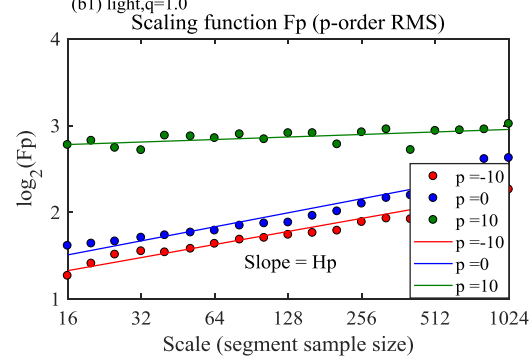

p-order Mass exponent

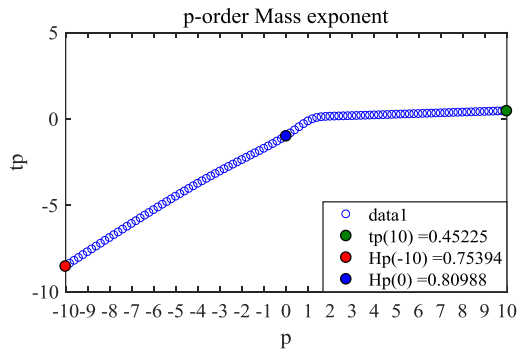

(b2) light, $\mathrm{q}=1.2$ Scaling function Fp (p-order RMS)

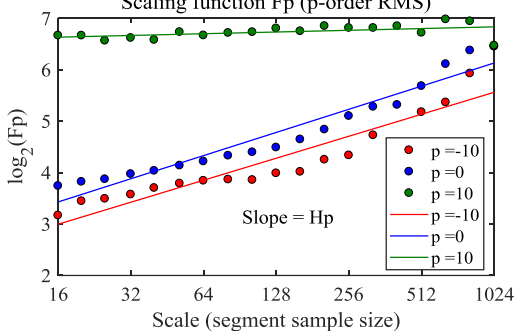

p-order Mass exponent

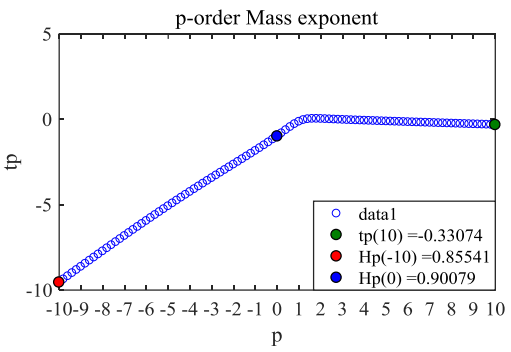

(b3) light, q=1.4 ${ }_{\text {Scaling function Fp (p-order RMS) }}$

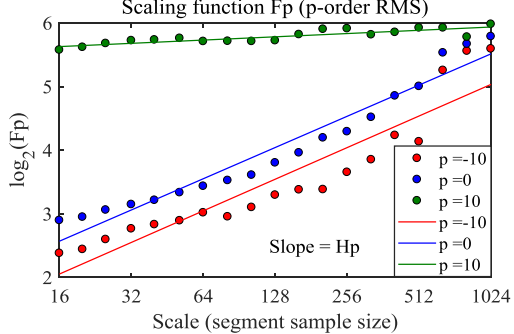

p-order Mass exponent

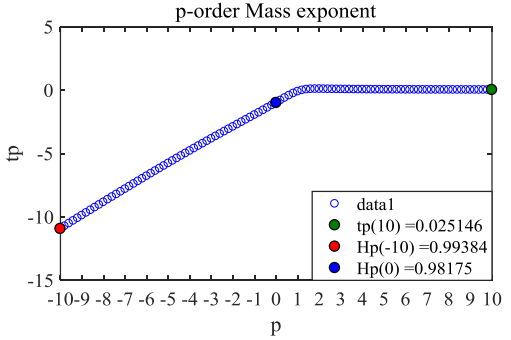

p-order Hurst exponent
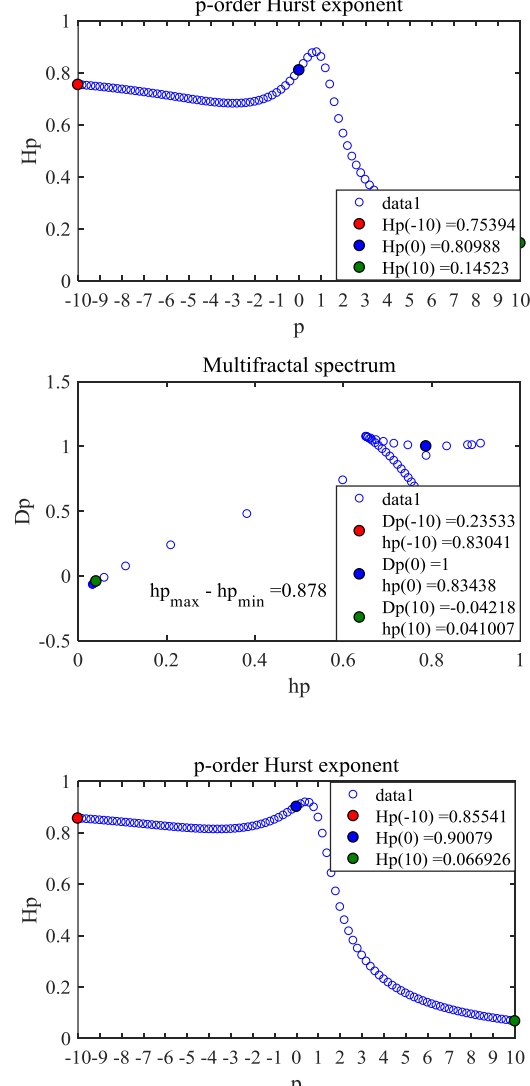

Multifractal spectrum
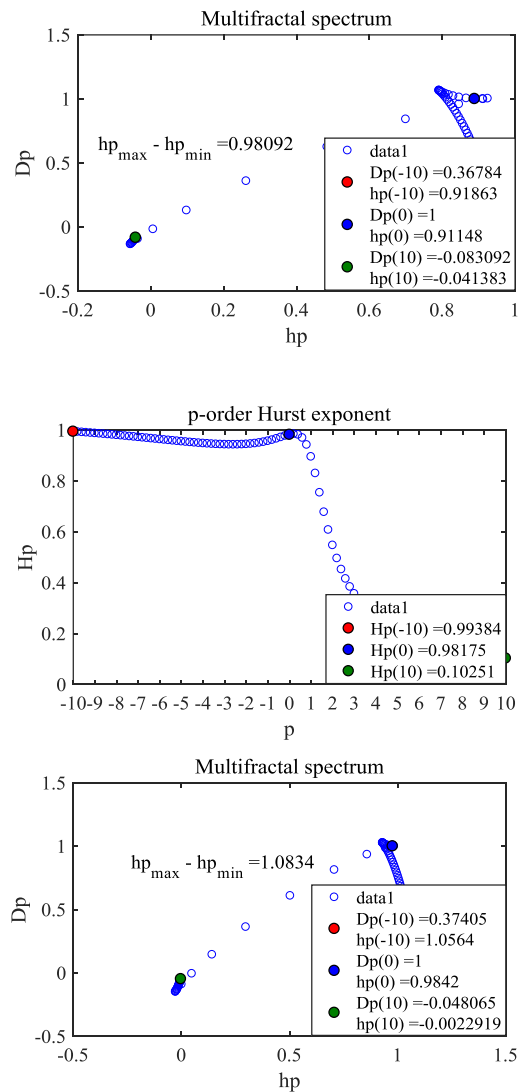

Figure 9. Cont. 

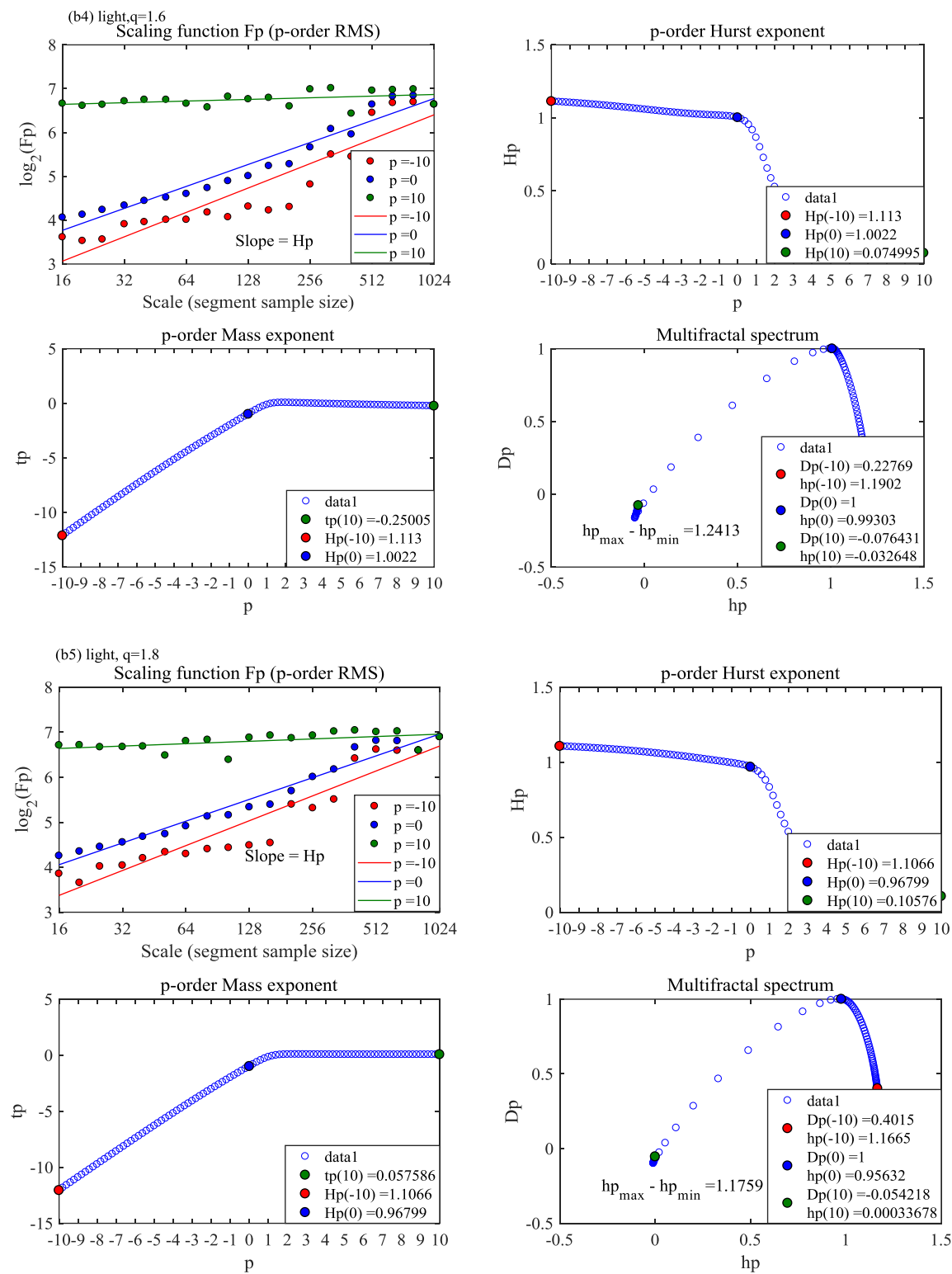

Figure 9. MF-DFA of heavy/light industry in different thresholds. (a1) Heavy, $q=1.0$; (a2) Heavy, $q=1.2$; (a3) Heavy, $q$ = 1.4; (a4) Heavy, $q$ = 1.6; (a5) Heavy, $q$ = 1.8; (b1) Light, $q=1.0$; (b2) Light, $q$ = 1.2; (b3) Light, $q=1.4$; (b4) Light, $q=1.6$; (b5) Light, $q=1.8$.

\subsection{Risk Estimation}

The hazard probability function $W_{q}(\Delta t \mid t)$ is an important method to estimate risk in recurrence interval analysis. Considering the fact that $t$ units of time have passed since last large volatility is greater than $q$ occurred, what fascinates us is the probability that the next large volatility greater than $q$ will occur within $\Delta t$ units of time. The hazard probability function is as follows:

$$
W_{q}(\Delta t \mid t)=\frac{\int_{t}^{t+\Delta t} P_{q}(\tau) d \tau}{\int_{t}^{\infty} P_{q}(\tau) d \tau}
$$

we can calculate the theoretical value of $P_{q}(\tau)$ with the parameters given in Table 2 if the distribution $P_{q}(\tau)$ fits with a stretched exponential index, and calculate the empirical value by rewriting $W_{q}(\Delta t \mid t)$ into: 


$$
W_{q}(\Delta t \mid t)=\frac{\operatorname{count}\left(t<\tau_{q} \leq t+\Delta t\right)}{\operatorname{count}\left(\tau_{q}>t\right)}
$$

where " $\operatorname{count}\left(\tau_{q}>t\right)$ " is the number of recurrence intervals greater than $t$ and "count $\left(t<\tau_{q} \leq t+\Delta t\right)$ " is the number of recurrence intervals greater than $t$ and less than $t+\Delta t$ for a given $q$.

Figure 10 is the hazard function; the symbols are empirical values and the curves are the theoretical values of $W_{q}(\Delta t=15 \mid t)$. We can observe that they are fitted very nicely and the discrepancy between empirical and theoretical curves decreases when $t$ increases. Furthermore, $W_{q}(\Delta t=15 \mid t)$ decreases with increasing $t$, confirming that recurrence intervals exhibit clustering behaviors and long-term memory between volatilities and theoretical values will overestimate the risk in a short time period. For a given threshold $q$, we can calculate the recurrence probability of extreme events.

For risk estimation, value at risk $(\mathrm{VaR})$ is widely applied. Here we use loss probability density function to define the risk at rising $q: \int_{-\infty}^{q} P(R) d R=P^{*}$, where $P(R)$ is the probability density function of normalized series $R(t)$, and $P^{*}$ is the rise probability. The mean recurrence interval $\bar{\tau}_{q}$ is:

$$
\bar{\tau}_{q}=\frac{1}{N_{q}} \sum_{i=1}^{\tau_{q}} \tau_{q, i}
$$
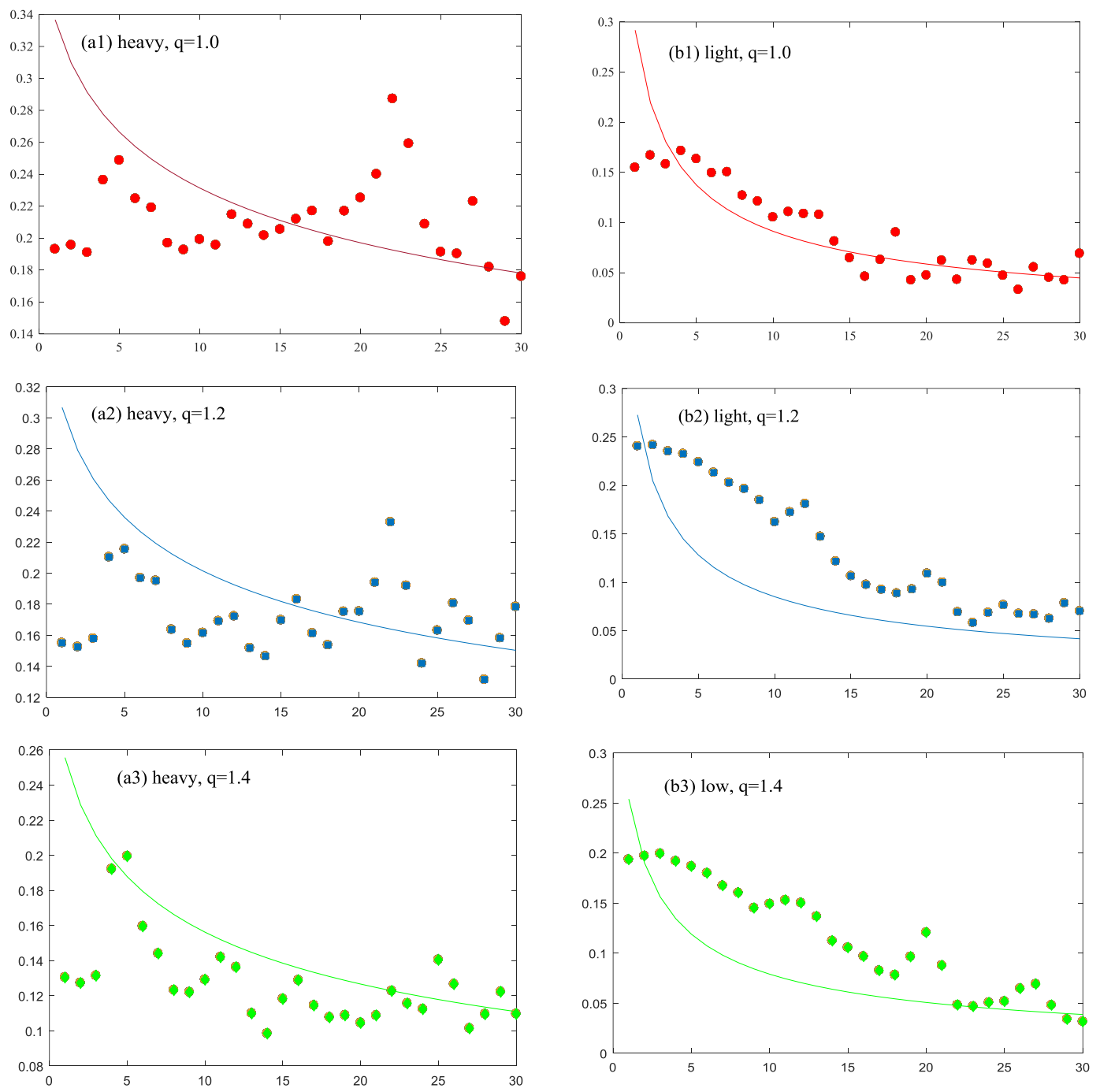

Figure 10. Cont. 

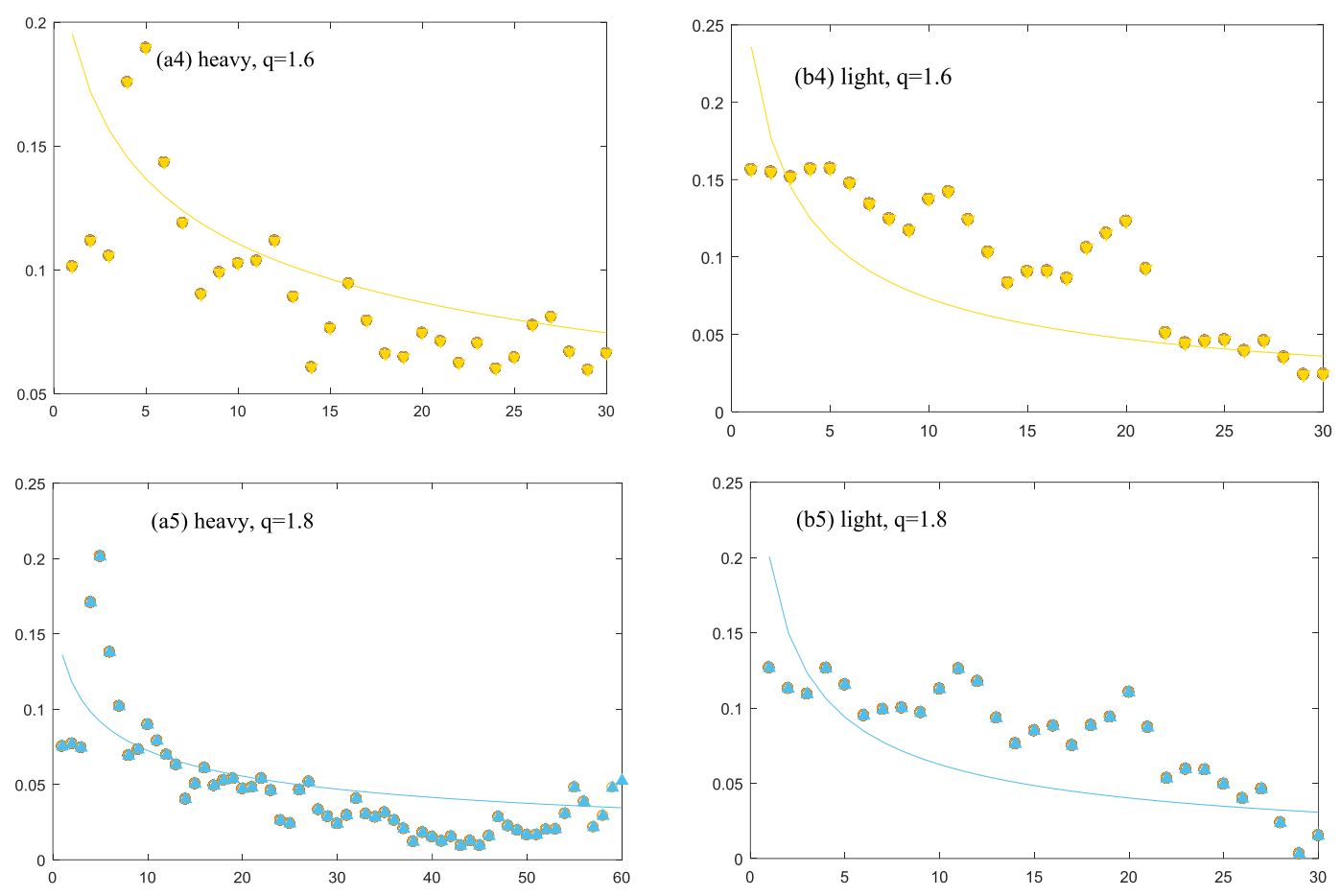

Figure 10. Theoretical (curves) and empirical (color symbols) value of $W_{q}(\Delta t=15 \mid t)$ (x-rays are $t$, y-rays are values of $\left.W_{q}(\Delta t=15 \mid t)\right)$.

$N_{q}$ is the number of recurrence intervals below the threshold $q, \sum_{i=1}^{\tau_{q}} \tau_{q, i}$ is the total number of recurrence returns. Then the relation between mean recurrence interval and $\mathrm{VaR}$ can be expressed as:

$$
1 / \bar{\tau}_{q}=\int_{-\infty}^{q} P(R) d R=\frac{\text { number of } R(t) \text { below } q}{\text { total number of } R(t)}
$$

Equation (16) means that one $/ \bar{\tau}_{q}$ defines the rise probability of $q$ which is depicted in Figure 11. If one wants to know the risk level at $1 \%$ probability of rise they can find the $q$ for $1 / \bar{\tau}_{q}=1 \%$, which is the VaR one is looking for.
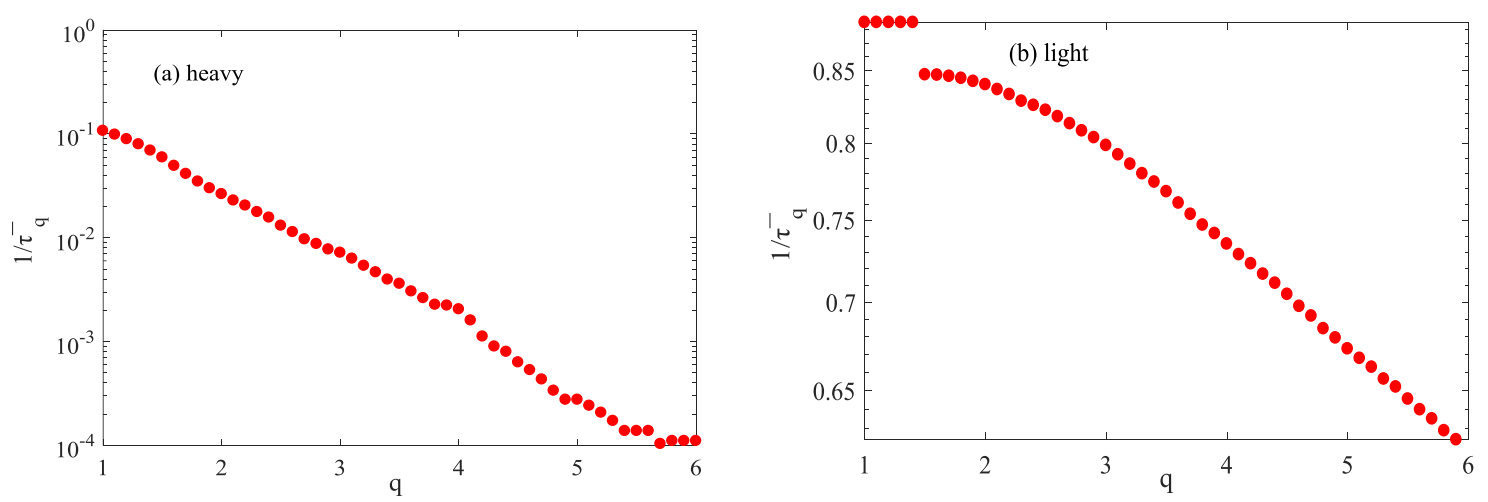

Figure 11. The reciprocal of mean recurrence interval one $/ \bar{\tau}_{q}$ as a function of threshold $q(q=1: 6)$. (a) Heavy; (b) Light. 


\section{Discussion}

In the context of China's new round of power reform, according to the empirical analysis above, we propose several suggestions for power supply companies in various regions of China to promote future management.

Firstly, based on the analysis of probability density function and risk estimation, we can see that the power load of light industry is more likely to fluctuate than for heavy industry in China. Such fluctuation difference means that the power companies need more intensive and meticulous maintenance of the electricity load in the light industry, which is supported by all analyses including the risk analysis. However, since the power load consumed by the heavy industry is much higher than that of the light industry at the same time interval, the management of the heavy industry should be more biased towards safety checks of the pre-process and the normative constraint of the overall operation flow instead of increasing the times of maintenance of the electricity load.

Secondly, power enterprises can make load and customer management based on the analysis of load data. Power companies can increase the communication with their clients, plan the line redundancy, enlarge load redundancy of the existing heavy industry and eliminate the risk of equipment damage caused by capacity loads. Also, the electric power enterprise should incorporate the improvement of electricity utilization rate into management assessment, through the introduction of clean energy and distributed energy, and improve energy supply structure, to cope with the effects of the large power enterprises' sudden peak with least environment negative externalities.

Thirdly, existing power companies should pay more attention to the fluctuation characteristics of different industries to realize optimal management expenditure. As we demonstrated in Section 4, the enterprises of two distinct industries in this study have some similarities in fluctuation pattern, which makes it possible to use similar management strategies for maintaining related equipment. Moreover, the difference between the two enterprises' load peaks allows the power companies to design different maintenance teams to eliminate frequency to optimize the cost of management and maintenance.

Finally, an electric power company can make use of the correlation between small and large fluctuations, especially small fluctuations, and provide them as a value-added services to the existing large power customer to increase corporate earnings in this competitive market. For example, using the current fluctuation trends, the power enterprises can fully expect the changes of large fluctuations according to the characteristics of small fluctuations in the relevant industries. Based on pre-judgment, power companies can design different energy storage or line maintenance and support strategies, pack these strategies into different packages, and offer them to energy consumers in the form of value-added services. It can improve the efficiency of regional energy utilization, optimize local network and equipment management of electric circuitry, and also can bring extra income for the electric power company and improve the survivability of the electric power enterprises under the market reform.

\section{Conclusions}

The paper uses recurrence interval analysis to investigate the property of recurrence intervals of electricity fluctuations of heavy/low industries in China for different thresholds using 15-min high-frequency data, attempting to understand the behaviors of large volatilities in different industries.

First, we observe the distribution functions of recurrence and find the results that for different thresholds, the probability density function fits the stretched exponential function. We found that there is scaling behavior in the distributions for different thresholds after the recurrence intervals are scaled with the mean recurrence interval. Then we use conditional probability density function and MF-DFA to investigate the short-term, long-term memory and multi-fractural characteristics separately, indicating that the clusters of recurrence intervals of volatilities are not only caused by present conditions, but also long-term correlations. Later, we apply recurrence interval analysis to evaluate the risk of heavy/light industries, which provide relatively accurate estimates of hazard and 
forge a link between loss possibility and VaR. Finally, we propose management suggestions to Chinese energy supply companies based on all previous analyses.

Of course, this paper still has deficiencies. For example, other forecasting methods could be used or more enterprises from heavy/light industry could be chosen to test the robustness of research results. These deficiencies could be perfected by subsequent researchers to help energy company administrators evaluate risk.

Acknowledgments: This research is supported by the China Social Science Fund (fund number 15AJL004, 15CJL048), the Fundamental Research Funds for the Central Universities (fund number 3214007103), the 111 Project (fund number B16040), and the Elementary Research Fund of Southeast University (fund number 2242017S10008).

Author Contributions: Chi Zhang conceived and designed the experiments; Zhengning Pu and Jiasha Fu performed the experiments; Chi Zhang and Jiasha Fu analyzed the data; Zhengning Pu contributed analysis tools; Chi Zhang wrote the paper.

Conflicts of Interest: The authors declare no conflict of interest.

\section{References}

1. Gong, L.; Zhang, S. The Inability of Japan to Adapt to China's Rise and China's Strategic Response. Contemp. Int. Relat. 2014, 24, 27-31.

2. Mingli, P. The Global Electricity Report in 2015. 2015. Available online: http://www.trqgy.cn/report/ 201512/25892.html (accessed on 29 December 2015).

3. China Electricity Council. Analysis and Prediction Report on National Electricity Demand and Supply in 2017. 2017. Available online: http:/ / www.cec.org.cn/yaowenkuaidi/2017-01-25/164285.html (accessed on 25 Januray 2017).

4. Hou, X.Y.; Qiu, W.; Ping, J.U.; Zhao, J.Q.; Luo, J.Y.; Zhu, H. Study of the Optimization of Under-frequency Load Shedding in Jiangsu Power Grid. Jiangsu Electr. Eng. 2008, 27. [CrossRef]

5. Ning, A.N.; Zhou, S.X.; Zhu, L.Z.; Wang, Q.H.; Zong-Xiang, L.U.; Wei, H.U.; Wang, X.Y. Analysis of 2006 Jiangsu power grid voltage stability influenced by load characteristics. Electr. Power 2006, 39, 16-20.

6. Xia, L.I. Regression Forecasting of the Power Load in Jiangsu Province. Value Eng. 2014, 3, 64-65.

7. Yang, J.Y.; Zhou, Q.; Zhao, H.D.; Tan, J. Affection study on load and electricity consumption of Jiangsu power grid during Spring Festival. Power Demand Side Manag. 2015, 17. [CrossRef]

8. Bunde, A.; Eichner, J.F.; Havlin, S.; Kantelhardt, J.W. Return intervals of rare events in records with long-term persistence. Phys. A Stat. Mech. Appl. 2004, 342, 308-314. [CrossRef]

9. Matthews, J.O.; Hopcraft, K.I.; Jakeman, E.; Siviour, G.B. Accuracy analysis of measurements on a stable power-law distributed series of events. J. Phys. A Gen. Phys. 2006, 39, 45. [CrossRef]

10. Chow, J. Power-Law Distributions In Events Involving Nuclear and Radiological Materials; Massachusetts Institute of Technology: Cambridge, MA, USA, 2009.

11. Clauset, A.; Shalizi, C.R.; Newman, M.E.J. Power-Law Distributions in Empirical Data. SIAM Rev. 2009, 51, 661-703. [CrossRef]

12. Burioni, R.; Gradenigo, G.; Sarracino, A.; Vezzani, A.; Vulpiani, A. Rare events and scaling properties in field-induced anomalous dynamics. J. Stat. Mech. Theory Exp. 2013, 2013, 1267-1279. [CrossRef]

13. Gillespie, C.S. A complete data frame work for fitting power law distributions. arXiv. 2014. Available online: https:/ /arxiv.org/abs/1408.1554 (accessed on 2 Januray 2018).

14. Sun, J.; Niu, D.; Li, C. Study on Chaos Characteristics of Electricity Price Based on Power-Law Distribution. Lect. Notes Electr. Eng. 2011, 121, 503-510.

15. Dologlou, E. Stability of a power law relation between characteristics of earthquakes and electric precursors. Nat. Hazards Earth Syst. Sci. 2012, 12, 1783-1787. [CrossRef]

16. Cardona, M.; Chamberlin, R.V.; Marx, W. The history of the stretched exponential function. Ann. Phys. 2010, 16, 842-845. [CrossRef]

17. Kisslinger, C. The stretched exponential function as an alternative model for aftershock decay rate. J. Geophys. Res. Solid Earth 1993, 98, 1913-1921. [CrossRef] 
18. Lee, K.; Siegel, J.; Webb, S.; Leveque-Fort, S.; Cole, M.; Jones, R.; Dowling, K.; Lever, M.; French, P. Application of the stretched exponential function to fluorescence lifetime imaging. Biophys. J. 2001, 81, 1265-1274. [CrossRef]

19. Laherrère, J.; Sornette, D. Stretched exponential distributions in nature and economy: "Fat tails" with characteristic scales. Eur. Phys. J. B Condens. Matter Complex Syst. 1998, 2, 525-539. [CrossRef]

20. Hagan, M.T.; Behr, S.M. The time series approach to short term load forecasting. IEEE Trans. Power Syst. 1987, 2, 785-791. [CrossRef]

21. McSharry, P.E.; Bouwman, S.; Bloemhof, G. Probabilistic Forecasts of the Magnitude and Timing of Peak Electricity Demand. IEEE Trans. Power Syst. 2005, 20, 1166-1172. [CrossRef]

22. Fumo, N.; Rafe Biswas, M.A. Regression analysis for prediction of residential energy consumption. Renew. Sustain. Energy Rev. 2015, 47, 332-343. [CrossRef]

23. Pérez-García, J.; Moral-Carcedo, J. Analysis and long term forecasting of electricity demand trough a decomposition model: A case study for Spain. Energy 2016, 97, 127-143. [CrossRef]

24. Bianco, V.; Manca, O.; Nardini, S. Electricity consumption forecasting in Italy using linear regression models. Energy 2009, 34, 1413-1421. [CrossRef]

25. To, W.-M.; Lee, P.K.C.; Lai, T.-M. Modeling of Monthly Residential and Commercial Electricity Consumption Using Nonlinear Seasonal Models-The Case of Hong Kong. Energies 2017, 10, 885. [CrossRef]

26. Li, Y.; Guo, P.; Li, X. Short-Term Load Forecasting Based on the Analysis of User Electricity Behavior. Algorithms 2016, 9, 80. [CrossRef]

27. Quilumba, F.L.; Lee, W.-J.; Huang, H.; Wang, D.Y.; Szabados, R.L. Using Smart Meter Data to Improve the Accuracy of Intraday Load Forecasting Considering Customer Behavior Similarities. IEEE Trans. Smart Grid 2015, 6, 911-918. [CrossRef]

28. Nogales, F.J.; Contreras, J.; Conejo, A.J.; Espínola, R. Forecasting next-day electricity prices by time series models. IEEE Trans. Power Syst. 2002, 17, 342-348. [CrossRef]

29. Park, D.C.; El-Sharkawi, M.; Marks, R.; Atlas, L.; Damborg, M. Electric load forecasting using an artificial neural network. IEEE Trans. Power Syst. 1991, 6, 442-449. [CrossRef]

30. Tepedino, C.; Guarnaccia, C.; Iliev, S.; Popova, S.; Quartieri, J. A Forecasting Model Based on Time Series Analysis Applied to Electrical Energy Consumption. Int. J. Math. Models Methods Appl. Sci. 2015, 9, 432-445.

31. Dong, B.; Li, Z.; Rahman, S.M.M.; Vega, R. A hybrid model approach for forecasting future residential electricity consumption. Energy Build. 2016, 117, 341-351. [CrossRef]

32. Liang, J.; Liang, Y. Analysis and Modeling for China's Electricity Demand Forecasting Based on a New Mathematical Hybrid Method. Information 2017, 8, 33. [CrossRef]

33. Cerjan, M.; Matijas, M.; Delimar, M. Dynamic Hybrid Model for Short-Term Electricity Price Forecasting. Energies 2014, 7, 3304-3318. [CrossRef]

34. Kandananond, K. Forecasting Electricity Demand in Thailand with an Artificial Neural Network Approach. Energies 2011, 4, 1246-1257. [CrossRef]

35. Hippert, H.S.; Taylor, J.W. An evaluation of Bayesian techniques for controlling model complexity and selecting inputs in a neural network for short-term load forecasting. Neural Netw. 2010, 23, 386-395. [CrossRef] [PubMed]

36. Ekonomou, L.; Oikonomou, D.S. Application and comparison of several artificial neural networks for forecasting the Hellenic daily electricity demand load. In Proceedings of the 7th WSEAS International Conference on Artificial Intelligence, Knowledge Engineering and Databases, Cambridge, UK, 20-22 February 2008; pp. 67-71.

37. Suh, D.; Chang, S. An Energy and Water Resource Demand Estimation Model for Multi-Family Housing Complexes in Korea. Energies 2012, 5, 4497-4516. [CrossRef]

38. Chang, P.-C.; Fan, C.-Y.; Lin, J.-J. Monthly electricity demand forecasting based on a weighted evolving fuzzy neural network approach. Int. J. Electr. Power Energy Syst. 2011, 33, 17-27. [CrossRef]

39. Azadeh, A.; Ghaderi, S.; Tarverdian, S.; Saberi, M. Integration of artificial neural networks and genetic algorithm to predict electrical energy consumption. Appl. Math. Comput. 2007, 186, 1731-1741. [CrossRef]

40. Ulagammai, M.; Venkatesh, P.; Kannan, P.; Padhy, N.P. Application of bacterial foraging technique trained artificial and wavelet neural networks in load forecasting. Neurocomputing 2007, 70, 2659-2667. [CrossRef]

41. Bashir, Z.; El-Hawary, M. Applying wavelets to short-term load forecasting using PSO-based neural networks. IEEE Trans. Power Syst. 2009, 24, 20-27. [CrossRef] 
42. Liao, G.-C.; Tsao, T.-P. Application of a fuzzy neural network combined with a chaos genetic algorithm and simulated annealing to short-term load forecasting. IEEE Trans. Evolut. Comput. 2006, 10, 330-340. [CrossRef]

43. Shi, C.K.; Yan, W.Q.; Zhang, X.H.; Zhang, B.; Fan, Y.H.; Tang, W. Heavy overload forecasting of distribution transformer during the spring festival based on BP network and grey model. J. Electr. Power Sci. Technol. 2016, 31. [CrossRef]

44. Forte, M.F.; Hanson, J.L.; Hagerman, G. North Atlantic Wind and Wave Climate: Observed Extremes, Hindcast Performance, and Extratropical Recurrence Intervals. In Proceedings of the 2012 Oceans, Hampton Roads, VA, USA, 14-19 October 2012.

45. Liu, C.; Dong, P.; Shi, Y. Recurrence interval of the $2008 \mathrm{Mw} 7.9$ Wenchuan earthquake inferred from geodynamic modelling stress buildup and release. J. Geodyn. 2017, 110, 1-11. [CrossRef]

46. Williams, R.T.; Goodwin, L.B.; Sharp, W.D.; Mozley, P.S. Reading a 400,000-year record of earthquake frequency for an intraplate fault. Proc. Natl. Acad. Sci. USA 2017, 114, 4893-4898. [CrossRef] [PubMed]

47. Bogachev, M.I.; Kireenkov, I.S.; Nifontov, E.M.; Bunde, A. Statistics of return intervals between long heartbeat intervals and their usability for online prediction of disorders. New J. Phys. 2009, 11, 063036. [CrossRef]

48. Huo, C.Y.; Lu, Y.; Huang, X.L.; Liu, H.X.; Ning, X.B. Multi-scale Recurrence Quantification Analysis of Heartbeat Interval Series in Healthy vs. Heart Failure Subjects. In Proceedings of the 2014 7th International Conference on Biomedical Engineering and Informatics (Bmei 2014), Dalian, China, 14-16 October 2014; pp. 347-352.

49. Xie, W.-J.; Jiang, Z.-Q.; Zhou, W.-X. Extreme value statistics and recurrence intervals of NYMEX energy futures volatility. Econ. Model. 2014, 36, 8-17. [CrossRef]

50. Suo, Y.-Y.; Wang, D.-H.; Li, S.-P. Risk estimation of CSI 300 index spot and futures in China from a new perspective. Econ. Model. 2015, 49, 344-353. [CrossRef]

51. Altmann, E.G.; Kantz, H. Recurrence time analysis, long-term correlations, and extreme events. Phys. Rev. E 2005, 71 (5 Pt 2), 056106. [CrossRef] [PubMed]

52. Yamasaki, K.; Muchnik, L.; Havlin, S.; Bunde, A.; Stanley, H.E. Scaling and memory in volatility return intervals in financial markets. Proc. Natl. Acad. Sci. USA 2005, 102, 9424-9428. [CrossRef] [PubMed]

53. Müller-Plathe, F. Coarse-graining in polymer simulation: From the atomistic to the mesoscopic scale and back. ChemPhysChem 2002, 3, 754-769. [CrossRef]

54. Yamamoto, Y.; Hughson, R.L. Coarse-graining spectral analysis: New method for studying heart rate variability. J. Appl. Physiol. 1991, 71, 1143-1150. [CrossRef] [PubMed]

55. Izvekov, S.; Voth, G.A. A multiscale coarse-graining method for biomolecular systems. J. Phys. Chem. B 2005, 109, 2469-2473. [CrossRef] [PubMed]

56. Bunde, A.; Eichner, J.F.; Kantelhardt, J.W.; Havlin, S. Long-term memory: A natural mechanism for the clustering of extreme events and anomalous residual times in climate records. Phys. Rev. Lett. 2005, 94, 048701. [CrossRef] [PubMed]

57. Elder, J.; Serletis, A. Long memory in energy futures prices. Rev. Financ. Econ. 2008, 17, 146-155. [CrossRef]

58. Chen, Z.; Ivanov, P.; Hu, K.; Stanley, H.E. Effect of nonstationarities on detrended fluctuation analysis. Phys. Rev. E 2002, 65 (4 Pt 1), 041107.

59. Hu, K.; Ivanov, P.C.; Chen, Z.; Carpena, P.; Stanley, H.E. Effect of trends on detrended fluctuation analysis. Phys. Rev. E 2001, 64 (1 Pt 1), 011114. [CrossRef] [PubMed]

60. Lin, A.; Ma, H.; Shang, P. The scaling properties of stock markets based on modified multiscale multifractal detrended fluctuation analysis. Phys. A Stat. Mech. Appl. 2015, 436, 525-537.

61. Peng, C.K.; Buldyrev, S.V.; Havlin, S.; Simons, M.; Stanley, H.E.; Goldberger, A.L. Mosaic organization of DNA nucleotides. Phys. Rev. E 1994, 49, 1685-1689. [CrossRef]

62. Sun, K.; Chen, X.; Cao, Y.; Han, Z. Research on the Fractal Characteristics of Prices in Electricity Market. In Proceedings of the IET International Conference on Advances in Power System Control, Operation and Management, Hong Kong, China, 30 October-2 November 2006; p. 418.

63. Sun, K.; Han, Z.X. Fractal feature of prices in California electricity market. Energy Eng. 2006, 5, 1-3.

64. Boeing, G. Visual Analysis of Nonlinear Dynamical Systems: Chaos, Fractals, Self-Similarity and the Limits of Prediction. Systems 2016, 4, 37.

65. Jiang, A.; Gao, J. Fractal analysis of complex power load variations through adaptive multiscale filtering. In Proceedings of the International Conference on Behavioral, Economic and Socio-Cultural Computing, Cracow, Poland, 16-18 October 2017; pp. 1-5. 
66. Sreenivasan, K.R. Fractals and Multifractals in Fluid Turbulence. Annu. Rev. Fluid Mech. 1991, $23,539-604$. [CrossRef]

67. Bogachev, M.I.; Eichner, J.F.; Bunde, A. Effect of nonlinear correlations on the statistics of return intervals in multifractal data sets. Phys. Rev. Lett. 2007, 99, 240601. [CrossRef] [PubMed]

68. Cao, G.; Cao, J.; Xu, L. Asymmetric multifractal scaling behavior in the Chinese stock market: Based on asymmetric MF-DFA. Phys. A Stat. Mech. Appl. 2013, 392, 797-807. [CrossRef]

69. de Benicio, R.B.; Stošić, T.; de Figueirêdo, P.H.; Stošić, B.D. Multifractal behavior of wild-land and forest fire time series in Brazil. Phys. A Stat. Mech. Appl. 2013, 392, 6367-6374. [CrossRef]

70. Liu, W.; Shang, J.; Zhou, W.; Wen, F.; Lin, Z. Evaluation of value-at-risk in electricity markets based on multifractal theory. Autom. Electr. Power Syst. 2013, 37, 48-54.

71. Gao, R.; Wang, F.; Liu, W. Competitive Electricity Price Characteristic Analysis Based On Multifractal Detrended Moving Average Analysis. In Proceedings of the 6th International Conference on Electrical and Control Engineering (ICECE2015) and The 4th International Conference on Materials Science and Manufacturing (ICMSM2015), Shanghai, China, 14-15 August 2015; pp. 129-134.

72. Jan, W.; Kantelhardt, S.A.Z.; Koscielny-Bundec, E.; Havlind, S.; Bunde, A.; Stanley, H.E. Multifractal detrended \$uctuation analysis of nonstationary time series. Phys. A Stat. Mech. Appl. 2002, 316, 87-114.

73. Murguia, J.S.; Pérez-Terrazas, J.E.; Rosu, H.C. Multifractal properties of elementary cellular automata in a discrete wavelet approach of MF-DFA. EPL Europhys. Lett. 2009, 87, 28003. [CrossRef]

74. Cardella, E.; Ewing, B.T.; Williams, R.B. Price volatility and residential electricity decisions: Experimental evidence on the convergence of energy generating source. Energy Econ. 2017, 62, 428-437. [CrossRef]

75. Ciarreta, A.; Muniain, P.; Zarraga, A. Modeling and forecasting realized volatility in German-Austrian continuous intraday electricity prices. J. Forecast. 2017, 36, 680-690. [CrossRef]

76. Wang, F.; Liao, G.P.; Li, J.H.; Li, X.C.; Zhou, T.J. Multifractal detrended fluctuation analysis for clustering structures of electricity price periods. Phys. A Stat. Mech. Appl. 2013, 392, 5723-5734. [CrossRef]

(C) 2018 by the authors. Licensee MDPI, Basel, Switzerland. This article is an open access article distributed under the terms and conditions of the Creative Commons Attribution (CC BY) license (http:// creativecommons.org/licenses/by/4.0/). 